\title{
Validation of the coastal storm risk assessment framework along the Emilia-Romagna coast
}

\author{
Clara Armaroli *, Enrico Duo \\ Department of Physics and Earth Sciences, University of Ferrara, Via Saragat 1, 44122 Ferrara, Italy
}

\section{A R T I C L E I N F O}

\section{Keywords:}

Coastal erosion

Coastal flooding

Exposure indicators

Hazard indicators

Coastal index

Coastal hotspot

\begin{abstract}
A B S T R A C T
The Italian coasts are threatened by coastal flooding and erosion. The Emilia-Romagna region coastline is exposed to marine storms because of its low-lying nature and massive urbanization. Regional managers need comprehensive tools for coastal storm risk assessment. The RISC-KIT Coastal Risk Assessment Framework (CRAF) provides a conceptual framework, which includes hazard, exposure and vulnerability evaluation, to implement a screening process able to identify littoral zones that can be classified as hotspots (Phase 1) and to successively rank the identified hotspots to select the most critical ones (Phase 2). This study includes the results of the implementation of CRAF Phase 1 in the Emilia-Romagna coast. The method is based on a Coastal Index approach, calculated for $1 \mathrm{~km}$ length coastal sectors, applied taking into account both hazard and exposure indicators. The general methodology was partly modified thanks to the strong collaboration with the End-User (Servizio Geologico Sismico e dei Suoli, SGSS) which provided data, suggestions and comments at every step of the implementation. The SGSS also provided data to validate the outcomes of the CRAF methodology. Thus, the critical areas identified by the CRAF were compared with historical (1946-2010) storm impacts, resulting in a reasonable agreement between the identified hotspots.
\end{abstract}

\section{Introduction}

The Italian peninsula has almost $8000 \mathrm{~km}$ of coastlines, of which more than $60 \%$ are low shores. The $34 \%$ of the Italian territory located in a corridor of $300 \mathrm{~m}$ from the shoreline is urbanised, with higher percentages in the regions facing the Adriatic sea (ISPRA, 2012). The effect of marine processes on the coastal area has therefore a great importance, as erosion and inundation hazards are increasingly threatening large portions of the coastline, human structures and the population. In fact, coastal inundation caused by storm events represents a major issue, especially in low-lying areas such as alluvial plains.

National and regional governments urge a comprehensive evaluation of coastal risk, to better manage coastal areas in terms of allocation of funds for coastal protection and definition of effective land-use plans (Viavattene et al., 2017, and references therein).

The Emilia-Romagna coastline (Fig. 1) is particularly exposed to erosion and inundation hazards (Armaroli et al., 2012; Perini et al., 2016) because of its low-lying nature and high coastal urbanization. Consequently, there is an increasing demand for effective methodologies to properly evaluate coastal risk, which in the RISC-KIT project was defined as the probability of a hazard and its impacts (consequences) (Viavattene et al., 2015).

The RISC-KIT project (Van Dongeren et al., 2017) provided a tool for coastal hotspot assessment and selection at the regional level: the Coastal Risk Assessment Framework (CRAF) (Viavattene et al., 2017). The Phase 1 of the tool provides a conceptual framework to implement a screening process able to identify areas that can be classified as hotspots, through the integration of hazard and socio-economic components. Then, the Phase 2 of the CRAF is applied to rank the identified hotspots to select the most critical ones. The CRAF method is described in the paper by Viavattene et al. (2017), together with a comprehensive review of different methodologies adopted to evaluate coastal risk and the main differences between the CRAF and previous methods.

In this paper the authors present the outcomes of the application of the CRAF Phase 1 along the Emilia-Romagna coast. The results were validated with historical data provided by the end-users involved in the project. Regional managers, land-use planners and decision-makers were indeed involved in all the phases of CRAF Phase 1 implementation, because of their awareness and knowledge of coastal characteristics and issues that are important and valuable. Furthermore, they made a lot of

\footnotetext{
* Corresponding author.

E-mail addresses: rmrclr@unife.it (C. Armaroli), duonrc@unife.it (E. Duo).
} 


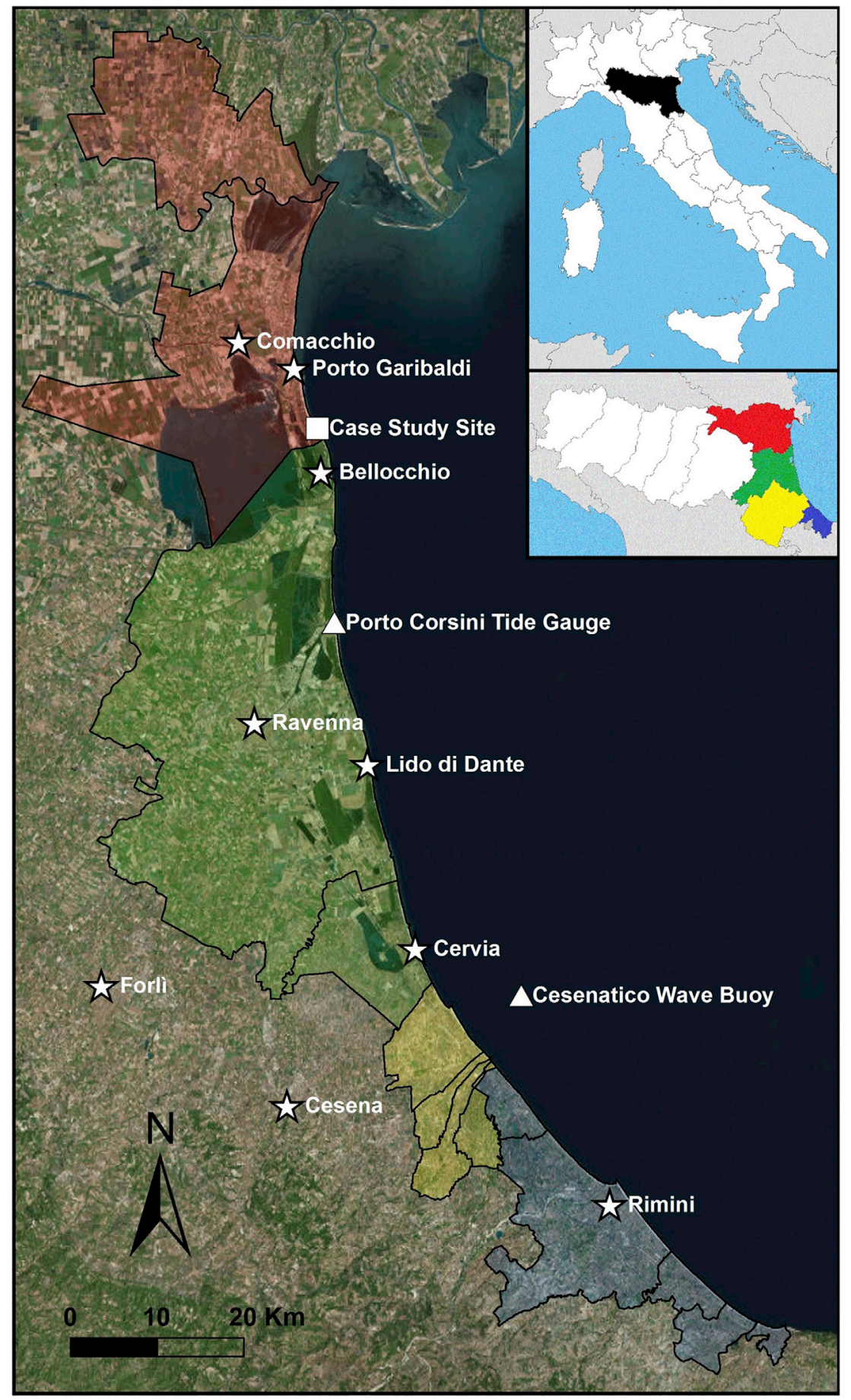

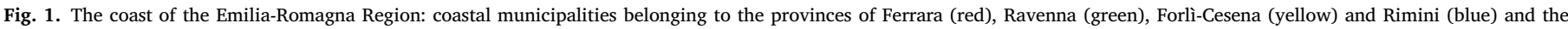
location of localities presented in the text is highlighted. (For interpretation of the references to colour in this figure legend, the reader is referred to the web version of this article.)

data available for the analysis and followed the key steps of the assessment, providing suggestions and comments. Finally it is important to point out that, although CRAF phase 1 was applied at the regional level, the application of CRAF phase 2 and other tools implemented in the RISC-KIT project was carried out in the area of Porto Garibaldi-Bellocchio (Ferrara province, Fig. 1), that was selected as the case study site (CSS hereafter) along the Emilia-Romagna coastline.

\section{Study area}

The coast of the Emilia-Romagna Region (RER hereafter) is located in northern Italy, facing the Adriatic Sea (Fig. 1). It is composed of almost $130 \mathrm{~km}$-long sandy beaches characterized by mild slopes and a dissipative nature (Perini et al., 2010a). The northern part of the coastline comprises the Ferrara and Ravenna provinces. The coastal corridor, defined as a strip of $\sim 2 \mathrm{~km}$ cross-shore width, is composed of wide and low-lying coastal plains, generally below MSL (minimum values of -2/-3 m; Perini et al., 2010b; Fig. 1). Furthermore it includes the last dune fields of the region that occupy almost $40 \%$ of this sector. The southern part includes the Forlì-Cesena and Rimini provinces (Fig. 1). The coastal corridor is characterized by $2-3 \mathrm{~m}$ elevations above MSL and the dunes have disappeared because of tourist pressure in the last 50 years (Sytnik 
and Stecchi, 2014). Over $60 \%$ of the coastline is protected by hard defence structures such as groins, breakwaters, submerged barriers, artificial embankments, dikes and rubble mound slopes.

The human pressure is significant (Lorito et al., 2010). The territory facing the sea is occupied by coastal villages and towns that, in the southern provinces, represent a continuous urbanization. The natural subsidence of the coastal area (composed of alluvial sediments) is dramatically increased up to $2 \mathrm{~cm} /$ year (Ravenna area, Fig. 1) by groundwater extraction for agriculture, human consumption, especially in the summer season, and gas extraction (Teatini et al., 2005, Taramelli et al., 2015). The marine flooding hazard significantly augmented over the last century due to the massive urbanization and exploitation of the coast for tourism. Besides, beach erosion is worsened by the negligible sediment supply from rivers (Ciavola et al., 2005), due to a strong human control and exploitation of water courses (Preciso et al., 2012) and the reforestation of the Apennines (Billi and Rinaldi, 1997).

The area is microtidal with a range between 80 and $90 \mathrm{~cm}$ (spring tides) and $30-40 \mathrm{~cm}$ (neap tides). The wave climate is of low energy (60\% of Hs below 1.0 m; IDROSER, 1996; Ciavola et al., 2007). Storm directions are from E-NE (Bora wind) and SE (Scirocco wind). Surge levels are an important element controlling total water levels measured during storms (Masina and Ciavola, 2011). The highest surge levels are generated by south-easterly winds that favour water piling in the northern Adriatic Sea, when combined with low barometric pressures caused by low-pressure weather systems. Masina and Ciavola (2011) found that the 1-in-10-year return period surge is $0.79 \mathrm{~m}$ and thus it can almost double the tidal range. High surge levels can cause extensive erosion and inundation when associated with storm waves (Armaroli et al., 2012). Storms can be energetic with the maximum-recorded wave height of $4.66 \mathrm{~m}$, measured during the 5-6 February 2015 storm, one of the most intense ever observed on the local wave buoy of Cesenatico (Fig. 1). Armaroli et al. (2012) identified critical storm thresholds for damages along the coast on the basis of historical data: 1) Hs $\geq 2 \mathrm{~m}$ and WL (surge + tide) $\geq 0.7 \mathrm{~m}$ for urbanised zones; 2 ) Hs $\geq 3.3$ and WL (surge + tide) $\geq 0.8 \mathrm{~m}$ for natural areas with dunes.

The most important business sector is represented by summer activities. Tourism is of the "sun-and-beach" type and the main economic asset is related to concessions. Concessions are private properties located on public beach areas that are granted to privates for commercial/tourism activities. Concessions are composed of permanent one-floor (i.e. the ground floor) buildings and other additional areas. Tourists can take advantage of a large number of services provided by concessionaires (e.g. showers, changing rooms, toilets, access paths to the sea, bar, restaurant, playgrounds and babysitting, volley/basket/mini soccer fields, gym, etc). Furthermore, concessionaires rent sun-chairs/beds and umbrellas to holidaymakers. Beaches in the summer season are occupied by a large number of sun-umbrellas, that are placed from the concession to the shoreline, to form a cross-shore and alongshore continuum. Concessions are present along almost $76 \%$ of the coastline.

\section{End-users know-how and expertise}

The regional authorities have been collecting information on the coastline since the half of the last century. The first Coastal Regional Plan dates back to the early 1980s (IDROSER, 1981) and includes physical information of the coastal area (evolution, sediment characteristics, topo-bathymetric data, type and location of coastal defences and their effectiveness, subsidence rates, etc) together with data on wave and wind climate, tide and surge analysis, a list and description of management practices and, finally, the relevant issues in terms of coastal protection. The most important hazards, such as coastal flooding and erosion, are also highlighted. The plan was compiled to list the interventions carried out along the coast, to propose new solutions and to provide a reference database for coastal managers and decision makers. Another Coastal Regional Plan was issued in 1996 (IDROSER, 1996). Several other reports describing the state of the coastline (main problems, interventions, etc) were issued since then.

The amount of data and information collected over the last 60 years is very large and is available also online (http://ambiente.regione.emiliaromagna.it/geologia/temi/costa), since the early 2000s, through a web-based platform (Coastal Information System, SIC). The regional Servizio Geologico Sismico e dei Suoli (SGSS hereafter) is responsible for data collection, validation, elaboration and online publication, and analyses remote sensing data (aerial photographs, Lidar, etc), as well as any other source of information, from desktop research to direct surveys and digitalization of archived records. Data collected are presented through a web-GIS tool, therefore it is possible to access a large number of geospatial datasets, e.g. land use information (derived from photointerpretation), medium-term shoreline variability, land subsidence rates, location of offshore sand deposits and a collection of storm events that caused damages along the coast, among many others. Data collection and validation is continuously carried out in order to update the web-GIS platform. Furthermore, data related to storms and their impacts are compiled in cooperation with the Civil Protection and local authorities to create a comprehensive database that includes detailed information on impacts, costs, extension of inundation, degree of erosion and type of emergency interventions performed during the event and in the aftermath. The first step towards the current practice of collecting detailed data on storm events is represented by the work carried out in the MICORE project (Ciavola et al., 2011; www.micore.eu) that led to the publication of a regional storm catalogue which includes the most significant and damaging events from 1946 to 2010 (Perini et al., 2011).

For what concerns coastal hazards, the RER runs an operational Early Warning System (EWS), also based on the critical storm thresholds defined above, that is used by the Civil Protection to evaluate wave and water level forecasts and their morphological impact along representative profiles located along the whole coastline. The EWS was developed in the framework of the MICORE project. More details can be found in Harley et al. (2016).

\section{Methodology}

The methodology adopted to apply CRAF Phase 1 is presented hereafter. The method to compute the extension and magnitude of the hazard component will be briefly described. The implementation of the exposure indicators will be described shortly. However, the key steps and definitions will be presented.

The CRAF Phase 1 methodology is based on the calculation of a Coastal Index $(\mathrm{CI})$ along a regional coastline $(\sim 100 \mathrm{~km})$ that is divided into sectors of almost $1 \mathrm{~km}$ alongshore length. The $\mathrm{CI}$ is computed for every $1 \mathrm{~km}$ coastal sector. The $\mathrm{CI}$ is a number ranging from 0 to 5 that allows the comparison between sectors to identify which sector(s) is (are) a hotspot(s). The CI is computed as Equation (1):

$C I=\left(i_{\text {hazard }} \cdot i_{\text {exposure }}\right)^{1 / 2}$

where $i_{\text {hazard }}$ is the hazard indicator and $i_{\text {exposure }}$ is the exposure index.

The first step for the computation of the CI is the hazard definition and the evaluation of its intensity. Then, the hazard indicator is represented by a number from 0 (no-hazard) to 5 (very high hazard) built through the scoring from 0 to 5 (none, very low, low, medium, high, and very high) of the hazard magnitude in each sector. If flooding and erosion are selected as main hazards, the hazard evaluation includes also the computation of the landward extension of the inundation (e.g. identification of flood-prone areas) and the shoreline retreat magnitude. Each hazard has to be considered separately.

The exposure index ranges from 1 to 5 and it is computed as Equation (2):

$i_{\text {exposure }}=\left(i_{\text {exp } 1} \cdot i_{\text {exp } 2} \cdot \ldots i_{\text {expn }}\right)^{1 / n}$

where $\mathrm{n}$ is the number of considered exposure indicators $\left(\mathrm{i}_{\exp }\right)$. The 
Table 1

Definition of the extreme events.

\begin{tabular}{|c|c|c|c|c|c|c|c|c|c|}
\hline ID & Event & $\mathrm{RP}$ [years] & Storm Surge [m] & Tide Level [m] & Wave Setup [m] & TWL $[\mathrm{m}]$ & $\mathrm{Hs}[\mathrm{m}]$ & $\mathrm{Tp}[\mathrm{s}]$ & Duration [hours] \\
\hline $\mathrm{T} 10$ & Freq. & 10 & 0.79 & 0.4 & 0.3 & 1.49 & 4.7 & 8.9 & 42 \\
\hline $\mathrm{T} 100$ & Low Freq. & 100 & 1.02 & 0.4 & 0.39 & 1.81 & 5.9 & 9.9 & 55 \\
\hline
\end{tabular}

exposure indicators are: utilities, transport networks, land use, business setting and the social status of the population. In general terms, the method consists in assigning to each sector a 1-to-5 score (non-existent or very low, low, medium, high, very high exposure) based on both location and importance/relevance of the indicator (the scoring has to be carried out separately for each indicator), and following ad-hoc scales implemented by the CRAF user, or already available methods or more general scales, like those proposed by Viavattene et al. (2017). For the RER coast, the proposed general scales were partly modified to consider already available datasets and methodologies, as explained in the following sections.

\subsection{Hazards and sectors definition}

The CRAF Phase 1 implementation is based on the event approach (Ferreira et al., 2017; Viavattene et al., 2017). Two main hazards are considered: inundation and erosion. The inundation hazard was taken into account on the basis of the data already available at the regional level, produced for the Floods Directive (2007/60/EC) by SGSS, and on the method described in the paper by Perini et al. (2016) that will be presented hereafter. The methodology followed to analyse the erosion hazard is along the lines of the general methods described in Viavattene et al. (2017) and will be briefly described in the next paragraphs.

Both hazards were evaluated using two extreme events, defined according to Table 1 and based on the methodology adopted by regional managers (Perini et al., 2016). The total water level (TWL, Table 1) was computed as the sum of different variables extracted from the literature: surge levels (Masina and Ciavola, 2011), wave set up elevations (Decouttere et al., 1998) and the astronomical mean high spring tidal level (IDROSER, 1996). The methodology adopted by SGSS for the computation of TWLs does not include run-up levels and the effect of land subsidence. These elements were not considered in the analysis because the regional authorities wanted to implement a simple and quickly replicable methodology (Perini et al., 2016; Sekovski et al., 2015). Wave characteristics associated to each return period are listed in Table 1 and, again, were extracted from the literature (IDROSER, 1996; Armaroli et al., 2012). The durations were selected by similarity with the most significant historical events that affected the regional coastline between 1946 and 2010, analysed in the MICORE EU Project (www.micore.eu; Perini et al., 2011).

Notably, each component (wave setup, surge and tide) taken into account to compute TWLs was statistically analysed and calculated in an independent way. Therefore, the extreme events are not the result of a combined probability analysis. Thus, they are most probably representative of less frequent events. For simplicity's sake, they are referred to as $\mathrm{T} 10$ and $\mathrm{T} 100$ hereafter.

To implement CRAF phase 1, the RER coast was subdivided into 106 sectors almost $1 \mathrm{~km}$ long, according to: (i) type of coast (natural, urbanised not protected, urbanised and protected); (ii) type of

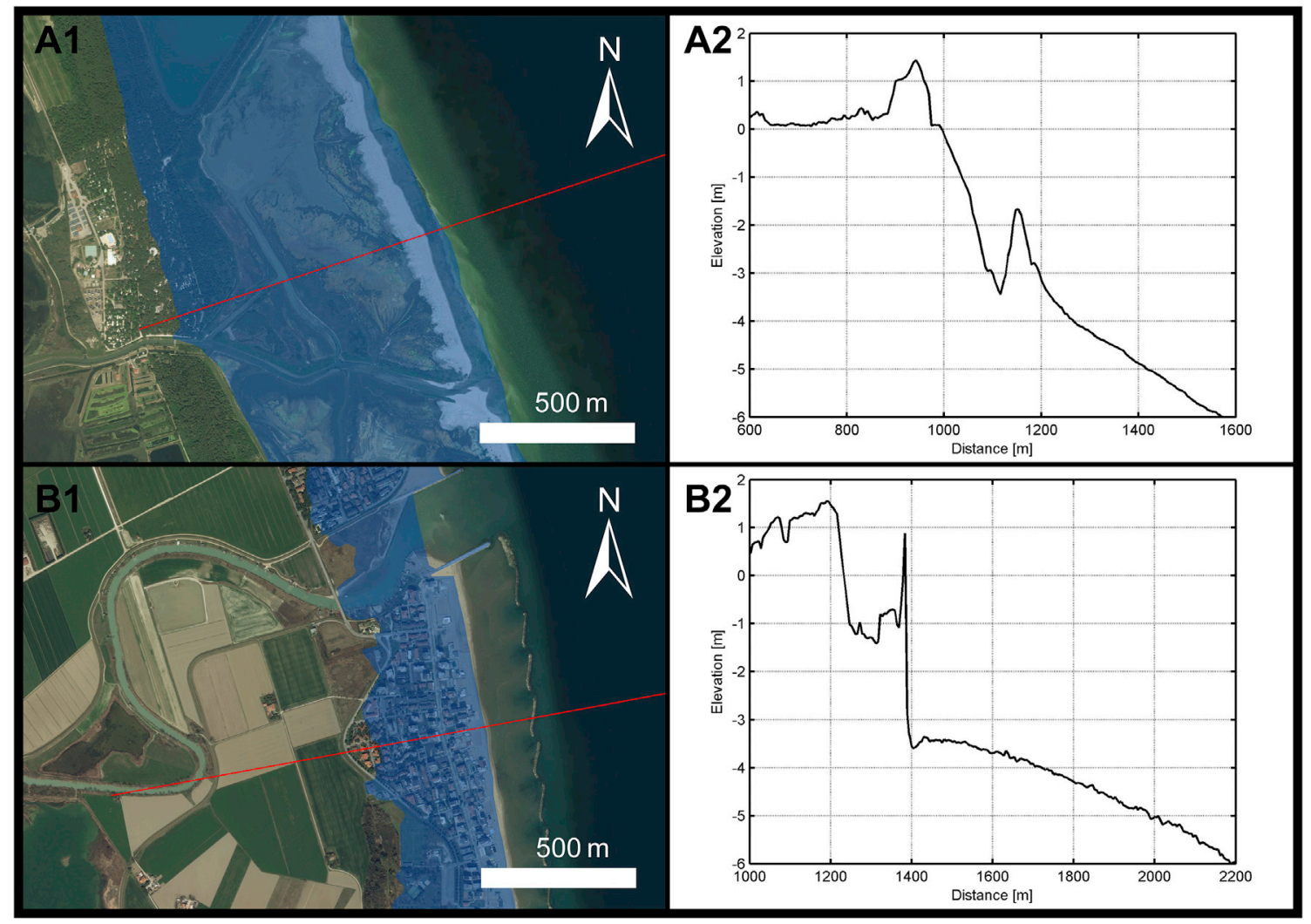

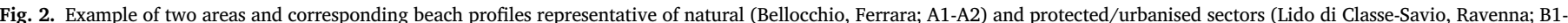

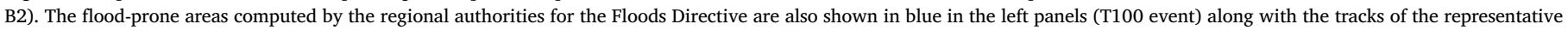
profiles. (For interpretation of the references to colour in this figure legend, the reader is referred to the web version of this article.) 
Table 2

Hazard indicators scoring for flooding and erosion.

\begin{tabular}{lllll}
\hline Flooding & & & Erosion & \\
\cline { 5 - 5 } D Value $[\mathrm{m}]$ & Score & & R Value $[\mathrm{m}]$ & Score \\
\hline$<-2.5$ & 0 & 0 & 0 \\
from -2.5 to -1.6 & 1 & & $<15$ & 1 \\
from -1.6 to -1.1 & 2 & from 15 to 19.9 & 2 \\
from -1.1 to -0.6 & 3 & & from 20 to 24.9 & 3 \\
from -0.6 to -0.1 & 4 & from 25 to 29.9 & 4 \\
$>-0.1$ & 5 & $>30$ & 5 \\
\hline
\end{tabular}

protections (rubble mound slopes, groins/jetties, emerged or semisubmerged breakwaters); (iii) presence of river outlets, navigation channels, marinas and ports. Ninety-four profiles were extracted from a 2012 topo-bathymetric DTM with $5 \times 5 \mathrm{~m}$ resolution provided by ENI (the national oil company). The number of profiles is less than the selected sectors, because a few areas have uniform characteristics alongshore (type of protection, beach characteristics, etc). Therefore, one profile was chosen to represent larger portions of the coast and the hazard indicators computed along the chosen segment were associated to more than one sector. Notably, the maximum distance between profiles is less than $2 \mathrm{~km}$. Each profile is representative of the average beach morphology (slope, height, etc) of every sector it belongs to. An example of representative coastal profiles for natural and protected beaches is shown in Fig. 2.

\subsection{Hazard indicators and extension}

\subsubsection{Flooding}

The hazard indicator $(D)$ for flooding was built as the difference between the total water level (TWL; Table 1) and the elevation of the rear part of the beach (e.g. the dune crest, where present, backshore, alongshore walking paths, etc) extracted from the cross-shore profiles described in the previous section. Negative values of $D$ showed that the backshore was higher than the TWL (representing the inundation of the beach only), therefore negative records defined a "low hazard" condition. Positive values of $D$, on the contrary, identified where the computed water level was higher than the rear part of the beach, thus where the coast is more exposed to flooding.

The obtained values were ranked and the corresponding scores are listed in Table 2. The values were classified considering both events (T10 and T100). The highest score (i.e. 5) was assigned to values above $-0.10 \mathrm{~m}$ to take into account the vertical resolution of the DTM. The values between the minimum and $-0.10 \mathrm{~m}$ were classified through the standard deviation of the values' distribution.

According to the methodology adopted by the regional authorities, beach inundation (i.e. negative values of the hazard indicator) is an important issue, as the beach is, along most of the coast $(76 \mathrm{~km}$ out of $100 \mathrm{~km}$ analysed for the CRAF phase 1), occupied by permanent concessions. Therefore, if the analysis showed that only the beach was inundated, it meant that the concessions (e.g. beach huts, bars, etc.) were likely to be damaged, which means that the analysed extreme events were able to always generate hazardous conditions ranging from very low to very high. Hence, there were no profiles with null hazard values.

The hazard extension, represented by the polygons that map the extension of flood-prone areas, was defined taking into account the maps produced for the Floods Directive by SGSS (Perini et al., 2016). The polygons were the result of an algorithm built through the model builder of ArcGIS. The model was based on the Cost Distance tool that was able to calculate the least path between a source (the 2010 shoreline) and landward areas. The tool calculated the distances between the shoreline and each grid cell of the DTM and assigned to each cell the lower value (i.e. least path) between all the distance values computed. The least paths were computed using the 2008 Lidar DTM (National Remote Sensing Programme) with $2 \times 2 \mathrm{~m}$ horizontal resolution and $0.2 \mathrm{~m}$ of vertical precision. The method allowed the exclusion of isolated areas (i.e. areas bordered by elements with elevations above the considered TWL) and the identification of preferential paths (i.e. passages) through which the water can inundate landward areas. The tool was calibrated and the maps were validated considering historical information on past and more recent flooding events for which the inundation extension was available. More details can be found in the paper by Perini et al. (2016). The polygons provided by SGSS (Perini et al., 2016; grid 5 in their Fig. 2) were used to define the domain of each sector where the exposure indicators were evaluated. The flooding hazard was calculated using the total water levels listed in Table 1 that are the same used by SGSS for the Floods Directive (T10 and T100).

\subsubsection{Erosion}

The hazard indicator related to beach erosion was calculated in agreement with Viavattene et al. (2017). The retreat $(R)$ of the shoreline was computed through the structural erosion function Equation (3), (Mendoza and Jimenez, 2006) and Equation (4):

$d V=C 1 \cdot J A \cdot d t+C 2$

$R=d V /\left(b+d^{*}\right)$

where $\mathrm{C} 1$ and $\mathrm{C} 2$ are calibration parameters of the erosion structural function, JA is the erosion potential predictor, $\mathrm{dV}$ is the potential eroded volume, $\mathrm{dt}$ is the event duration, $\mathrm{b}$ is the elevation of the berm and $\mathrm{d} *$ is the representative depth at which the erosion is null (Jiménez et al., 2015).

The general procedure was:

- identification of the type of profile (natural, urban, protected, or not protected, by breakwaters or rubble mound attached slopes);

- identification of the morphological features along the profile (submerged and emerged slopes, shoreline, berm height, dune features, etc);

- calculation of the JA erosion potential Equation (3) using proper wave conditions (i.e. taking into account the presence of coastal protections);

- calculation of the representative shoreline retreat Equation (4).

The procedure was applied with the following assumptions and simplifications: (i) the mean sediment diameter (D50) was assumed constant $(0.23 \mathrm{~mm})$ for the whole coastal region, (ii) the $\mathrm{d} *$ term was set equal to a water depth of 1 , (iii) the linear coefficients ( $\mathrm{C} 1$ and $\mathrm{C} 2$ ) of the structural function were set equal to 6.1 and 29.4, respectively and, (iv) for protected beaches (breakwaters), the attenuation effect of the structures was taken into account following the method described by Armaroli et al. (2009) which is based on Van der Meer and Daemen (1994).

The D50 was chosen on the basis of the information available in the literature (e.g. Armaroli et al., 2009) and considering a sediment analysis (unpublished) implemented in winter 2014-2015 in several areas along the Ferrara and Ravenna coasts. The D50 information, although only available for some tracts along the coast, was applied uniformly to the whole coastline for consistency's sake. The $\mathrm{C} 1$ and $\mathrm{C} 2$ values were chosen on the basis of the correlation function between the calculated JA.dt and the eroded volumes computed with a morpho-hydrodynamic model (XBeach 1D) for 20 (10 natural and 10 protected) representative profiles of the regional coast, forced with the probabilistic events listed in Table 1 . The modelling was also used to assess $\mathrm{d}^{*}$, through the qualitative analysis of the resulting post-storm profiles. Notably, the berm height along the coast varies from 0.8 to $1.2 \mathrm{~m}$. In some coastal sectors the retreat was assumed $0 \mathrm{~m}$ because of the presence of attached rubble mounds slopes. Notably, the total water level was not taken into account.

The hazard indicator scores were assigned according to the shoreline retreat values obtained from the analysis of both events $(0-57 \mathrm{~m}$ for T10; 0-68 $\mathrm{m}$ for T100). The scores were assigned following Table 2. Two 
Table 3

Type of utilities and transport networks in flood-prone areas and corresponding scores.

\begin{tabular}{lcll}
\hline $\begin{array}{l}\text { Type of utility network in flood } \\
\text { prone areas }\end{array}$ & Score & $\begin{array}{l}\text { Type of transport network in } \\
\text { flood prone areas }\end{array}$ & Score \\
\hline None & 1 & $\begin{array}{l}\text { Absence of transport network or } \\
\text { dirt/local road }\end{array}$ & 1 \\
$\begin{array}{l}\text { Distribution substation } \\
\text { (electricity and water) }\end{array}$ & 2 & $\begin{array}{l}\text { Transport road network with } \\
\text { local importance }\end{array}$ & 2 \\
$\begin{array}{l}\text { Primary substation } \\
\text { (electricity) }\end{array}$ & 3 & $\begin{array}{l}\text { Transport road network with } \\
\text { regional importance } \\
\text { Grid (electricity bulk supply }\end{array}$ & 3 \\
point) or aqueduct (water) & 4 & $\begin{array}{l}\text { Transport road network with } \\
\text { national importance/motorway }\end{array}$ & 4 \\
$\begin{array}{l}\text { Electricity super grid OR } \\
\text { electricity bulk supply } \\
\text { point + aqueduct OR }\end{array}$ & 5 & $\begin{array}{l}\text { Transport train networks and/ } \\
\text { or train network + national } \\
\text { importance road network }\end{array}$ & 5 \\
\hline
\end{tabular}

assumptions were applied considering the obtained shoreline retreat values: (i) erosion values below $15 \mathrm{~m}$ were scored 1 ; (ii) erosion values above $30 \mathrm{~m}$ were scored 5 . The values were classified dividing the interval between the selected minimum and maximum into 3 classes of $5 \mathrm{~m}$ each to take into account the beach occupation in the summer season, when sun-umbrellas and chairs are placed on the beach in parallel rows of 3-5 m cross-shore width. Finally, the 0 score was assigned to areas protected by attached structures (i.e. rubble mounds).

The hazard extension was defined by a $10 \mathrm{~m}$ buffer zone landward from the limit of the maximum shoreline retreat line, sector by sector. The $10 \mathrm{~m}$ buffer zone identified the area where the exposure indicators were calculated. It was chosen according to the methodology adopted to define the Storm Impact Indicators (SIIs) along the coast, implemented in the MICORE project (Ferreira et al., 2009; Ciavola et al., 2011) and that are part of the regional EWS (Harley et al., 2016).

\subsection{Exposure indicators}

For what concerns utilities, the location of aqueducts, wastewater treatment plants, energy distribution/supply stations was mapped along the coastal area. The same mapping was carried out for the transport network, considering roads with different importance and the railway line. The exposure indicators for utilities and transports were then built following Table 3 considering their location and importance. For the erosion hazard, the exposure indicators of utilities and transport were scored 1 or 2 , because no one or less important utilities and roads were located into the buffer zone.

Land use data were provided by SGSS and are represented by polygons derived from the photo-interpretation of 2008 aerial images mapped at 1:5 000 scale. This, compared to the Corine Land Cover dataset (Viavattene et al., 2017), ensured a more detailed definition of specific typologies of the regional domain (e.g. concessions). The values assigned to each land use typology were chosen according to the methodology adopted by SGSS to produce flood risk maps for the Floods Directive (Perini et al., 2016). Each type of land use was valued from 1 to 4 (i.e. 1 = low, 4 = high). The regional authorities decided to consider areas occupied by human-related activities (e.g. concessions, residential areas, industrial zones, etc) as highly valuable and natural sites (e.g. areas without human occupation, beach and dunes, marshes, etc) as less valuable, according to Chapter 3 , article 6 , of the Floods Directive $(2007 / 60 / C E)$. Therefore the valuation is human-centred. The scores of each sector were assigned considering the "area $\mathrm{x}$ value" results of each sector, where the area is represented by the areal extension of each flood-prone typology, in every sector, according to the flood maps provided by SGSS, multiplied by its value and then summed. The resulting values were divided into 5 classes through the natural breaks method of ArcGIS and considering both return periods. The same LU data were used to implement the exposure indicator for erosion, but only the typology "concession" was affected. The affected concessions were only a few. The obtained surface values were then scored as indicated in Table 4.
Table 4

Land Use characteristics and corresponding scores (erosion hazard).

\begin{tabular}{ll}
\hline Score & LU area $\left(\mathrm{m}^{2}\right)$ into buffer zone \\
\hline 1 & 0 (sectors with Ports/Marinas or protected by rubble mound attached slopes) \\
2 & 0 (sectors along natural areas with dunes) \\
3 & 0 (sectors along urbanised zones with concessions or concessions among \\
& dunes) \\
4 & $\leq 700$ \\
5 & $>700$ \\
\hline
\end{tabular}

The business settings exposure indicator was built considering the percentage of tourist arrivals in each municipality with respect to the total number of arrivals along the coast, to take into account the sun-andbeach tourist asset. Data were derived from the database of ISTAT with information from 2014. Each sector was assigned the score built as it follows: 1 = natural areas/restricted areas (e.g. military zones); 2 to 4 = dividing the obtained percentages (from 10 to $30 \%$ ) into equal intervals; $5=$ to the national level business figure.

It is worth mentioning that the Social Vulnerability Index was represented by an index, calculated for the whole Italian territory at the municipality level, defined by the National Institute of Statistics (ISTAT; www.ottomilacensus.istat.it). The index is named "Indice di Vulnerabilità Materiale e Sociale", that can be translated into "Social and Economic Status Vulnerability Index (ISEV)". The ISEV takes into account indicators of the social and economic status of families similarly to the UK Social Vulnerability Index (Tapsell et al., 2002). The score assigned to each sector is based on the range of ISEV values at the national level. Because the RER coastal municipalities do not show large differences with respect to ISEV values, the same score was assigned to the totality of sectors (i.e. $=3$ ).

\section{Results}

A sector was defined critical when its Coastal Index (CI) was higher than 2.5. It was decided to consider $\mathrm{CI}>2.5$ to take also into account endusers' comments to the obtained CIs maps. The end-users indeed stated that the identified critical sectors were consistent with well-known critical areas for both flooding and erosion, pointing out areas with CI close or above 2.5. A hotspot is defined hereafter as one or a set of adjacent sectors with CIs above the chosen threshold. The hotspots in the regional domain were evaluated with the End-Users and then two of them were further studied in the CRAF Phase 2 in order to select the most critical site (Viavattene et al., 2017).

The results of the CRAF Phase 1 coastal screening process are summarized in Tables 5 and 6 , in terms of statistics and frequency distribution of the sectors' CI, respectively. The locations of the critical areas will be shown in Section 6 for validation purposes.

\subsection{Flooding}

With reference to Table 5, the CI for flooding ranged from 1.20 to 3.78 considering both events. The average amongst the sectors increased from 2.21, for T10, to 2.61, for T100. Standard deviations were 0.61 and 0.67 for $\mathrm{T} 10$ and $\mathrm{T} 100$, respectively.

Considering Table 6, no sector showed null values of CI. The percentage of critical areas ( $\mathrm{CI}>2.5$ ) with respect to the totality of sectors

Table 5

Statistics of the CI values for flooding and erosion hazards for the 106 sectors.

\begin{tabular}{llllll}
\hline $\begin{array}{l}\text { Coastal Index } \\
\text { Statistics [-] }\end{array}$ & \multicolumn{2}{l}{ Flooding } & & \multicolumn{2}{l}{ Erosion } \\
\cline { 2 - 3 } \cline { 6 - 6 } & T10 & T100 & & T10 & T100 \\
\hline Min. & 1.20 & 1.20 & & 0.00 & 0.00 \\
Max. & 3.68 & 3.78 & & 3.07 & 3.27 \\
Mean & 2.21 & 2.61 & & 2.14 & 2.29 \\
St. Dev. & 0.61 & 0.67 & & 0.77 & 0.82 \\
\hline
\end{tabular}


Table 6

Distribution of the CI for flooding and erosion hazards for the 106 sectors.

\begin{tabular}{llllll}
\hline $\begin{array}{l}\text { Coastal Index } \\
\text { Distribution [\%] }\end{array}$ & \multicolumn{2}{l}{ Flooding } & & \multicolumn{2}{l}{ Erosion } \\
\cline { 2 - 3 } & T10 & T100 & & T10 & T100 \\
\hline $\mathrm{CI}=0$ & 0.0 & 0.0 & & 10.4 & 10.4 \\
$0<\mathrm{CI}=1.5$ & 14.2 & 8.5 & & 0.0 & 0.0 \\
$1.5<\mathrm{CI}=2.5$ & 60.4 & 29.2 & 69.8 & 51.9 \\
$2.5<\mathrm{CI}=3.5$ & 23.6 & 50.9 & & 19.8 & 37.7 \\
$3.5<\mathrm{CI}=4.5$ & 1.9 & 11.3 & & 0.0 & 0.0 \\
$4.5<\mathrm{CI}=5$ & 0.0 & 0.0 & & 0.0 & 0.0 \\
Total & 100 & 100 & & 100 & 100 \\
\hline
\end{tabular}

was $25.5 \%$ for $\mathrm{T} 10$ and $62.2 \%$ for T100. Amongst them, the 1.9 and the $11.3 \%$ of the 106 sectors showed CI higher than 3.5, for T10 and T100 respectively.

The authors highlight that the LU exposure indicator, along with the hazard one, resulted the main driving factor of the final CI values for most of the sectors, as the other exposure indicators resulted lower than 3 . The analysis identified six hotspots macro-areas for T10 and five for T100. Specifically, the critical areas for T10 were (from north to south, Fig. 1): 1) the southern portion of the Ferrara province; 2) the Ravenna province where the port of Porto Corsini is located; 3) the Lido di Dante area (a recent study on the area can be found in (Harley and Ciavola, 2013); 4) part of the Cervia municipality; 5) all the municipalities of the Forlì-Cesena province and 6) the area close to the navigation channel of Rimini. As expected, the extension of the critical areas largely increased for T100, because the critical sectors for T10 located in the central part of the coast (i.e. number 4 and 5 of the previous list) merged to create a continuous hotspot Fig. 3. Overall, the central area resulted very critical and included almost $20 \mathrm{~km}$ of urbanised coastline The northern/southernmost parts of the coast were mostly scored around 2, therefore were excluded from the list of critical zones.

\subsection{Erosion}

With reference to Table 5, the $\mathrm{CI}$ for erosion ranged from 0 to 3.27 , considering both events. The average amongst the sectors increased from 2.14 for T10 to 2.29 for T100. Standard deviations were 0.77 and 0.82 for T10 and T100, respectively.

Considering Table 6 , the $10.4 \%$ of the 106 sectors showed null CI and were the sectors with attached rubble mounds. The percentage of critical areas (CI > 2.5) was $19.8 \%$ for T10 and $37.7 \%$ for T100. No sector's CI resulted higher than 3.5 for both events.

The authors report that, also for the erosion hazard, the LU exposure and the hazard indicators were the main driving factors of the final CI values for most of the sectors. The analysis showed that there are several hotspots for T10 that largely increased for T100.

\section{Validation}

The maps, for both hazards and both tested events, were shown to decision makers and land use planners of SGSS, and they agreed that the critical areas identified along the coast corresponded to zones that are historically known as being prone to flooding and/or erosion impacts. Furthermore, a comparison was made between the results of the CRAF and the location of the areas affected by a huge storm that occurred in 5-6 February 2015 and that caused extensive erosion, flooding and economic damages along the coastline. Even if quantitative results based on the collected information on the impacts caused by the storm were not available, the hotspots identified with the CRAF are consistent with the

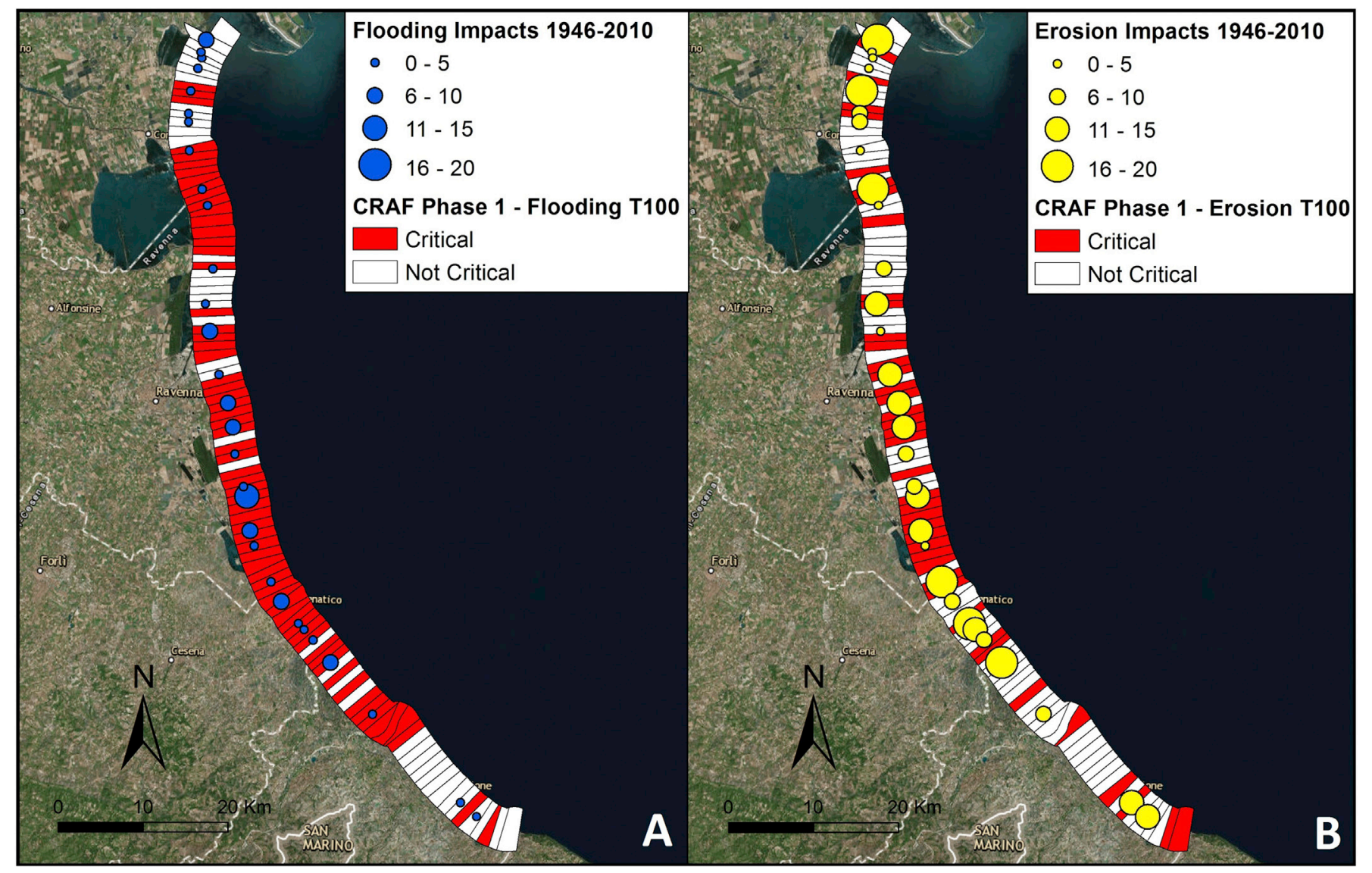

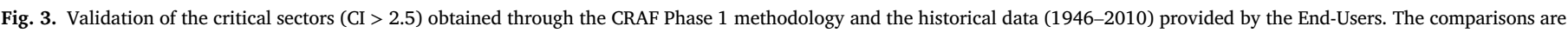
shown for both flooding (A) and erosion (B) hazards. 
zones affected by the February event (Perini et al., 2015; Trembanis et al., 2017, under review).

A more accurate evaluation of the validity of the CI maps derived from the comparison between the historical (1946-2010) information collected by SGSS (Perini et al., 2011) and the identified critical areas for the T100 scenario. SGSS did an evaluation of the number of inundation and erosion events that affected specific areas along the coast between 1946 and 2010. The data are available also in the web-GIS impact-oriented database of RISC-KIT (Ciavola et al., 2017). The results are shown in Fig. 3, along with the critical areas identified with the CRAF for the T100 event, for both hazards. To note that the symbols related to the historical information (circles) are located in the proximity of places that were historically affected, not in the exact location where each impact occurred. Therefore, they should be considered as an indication of critical areas in their surroundings. Furthermore, the symbols' size represents the number of inundation and erosion events, disregarding any other information on the magnitude of the storms. The historical information was collected taking into account the type of hazard and the impacts registered along the coast. Therefore, the comparison between the two datasets (historical data and CI maps) is appropriate.

With reference to Fig. 3, an agreement between the identified critical areas and the historical information occurs when a circle is located inside a critical sector plus the two adjacent sectors, 1 north and 1 south, to take into account the fact that each circle identifies the impact of storms to its surroundings. Thus, each circle is compared to a stretch of coast of about $3 \mathrm{~km}$ ( 3 sectors). It follows that for both hazards, on the basis of historical records, 74 out of 106 sectors can be considered critical.

Considering the flooding hazard (Fig. 3A), the T100 scenario highlighted 66 out of 106 critical sectors. For $71.2 \%$ of them a correspondence with historical records was found. Considering critical (47 sectors) and not critical (13 sectors) areas in the agreement evaluation, the $56.6 \%$ of the sector showed consistent results.

As an example, the Porto Garibaldi beach, located northward from the Porto Garibaldi navigation channel, is identified as critical for T100. The area was affected by huge storms in the past, also confirmed in Garnier et al. (2017). In fact, the town of Porto Garibaldi, formerly called Magnavacca, was already present in the 17th century and records of the effect of marine storms were found into historical documents. A good agreement was also found in the southern area of Lido di Spina and at the Bellocchio marsh.

The most significant discrepancy between the historical data and the critical sectors was found in the northern part of the region (the 6 northernmost sectors), Ferrara province (Fig. 3A). Several sites showed a large number of inundation events but they were not hotspot in the CRAF. The reason for the discrepancy can be explained as it follows: the northern part of the Ferrara province historically experienced a large number of inundations that led to the decision to elongate northwards the artificial coastal defences (through the construction of wood groins, alongshore earth and geotextile dikes) that, at present, are able to protect the area from flooding. The additional protection structures were built starting from the 1990s. Therefore, as the CRAF is based on present topographic data, the areas that are protected by coastal structures resulted non critical, while, historically, they were affected by significant flooding events. The hazard maps produced by SGSS (Perini et al., 2016) with the least-path analysis show, in fact, that the area is not flood-prone, due to the presence of the protection structures. The overall agreement (critical and not critical sectors) between the CRAF outcomes and the historical records for flooding improved to $61 \%$ if the 6 northernmost sectors are removed from the comparison.

Considering the erosion hazard (Fig. 3B), the critical areas for T100 were 40 out of 106 sectors. A correspondence with the historical records was found for 28 of them (70\%). In general, the correspondence between the historical information and the CRAF results, considering the critical areas (28 sectors) and the not critical ones (20 sectors), was $45.3 \%$.

Several sectors belonging to the RISC-KIT CSS (i.e. Porto Garibaldi -
Bellocchio, Comacchio) resulted critical, especially in the area of Lido di Spina south and at the Bellocchio marsh. The results are consistent with the historical information, because the area is a well-known hotspot of erosion. The site is, in fact, the target of regular nourishment practices (Nordstrom et al., 2015). Furthermore, the beach at the Bellocchio marsh is retreating and shows large overwash fans in fast development during the last decade (Bertoni et al., 2015).

It is important to underline that the main discrepancies between registered erosion events and the identified critical sectors occurred along areas protected by rubble mounds. These areas were mostly impacted before the construction of the defences. According to the methodology adopted, they show $\mathrm{CI}=0$. Another significant inconsistency was represented by the two southernmost sectors (Fig. 3B). In fact, two critical sectors were identified, but they do not correspond to the historically affected areas.

\section{Conclusions}

The analysis carried out to implement the CRAF Phase 1 through the event approach included a series of information, provided by the EndUsers, which are significant along the coast of the EmiliaRomagna region.

It was possible to evaluate the exposure to flooding and erosion of different assets. The results showed that utilities and transports were most probably not affected by flooding and erosion, and that the social and economic status of families was an important aspect but has almost uniform values along the coast. The business sector was, on the contrary, a key element, because a large part of the regional economy is based on the coastal tourist sector. However, the land use exposure and the hazard indicators were the driving elements for the identification of critical areas. Most of the coast resulted exposed to both hazards. This is related to the large urbanization, to the low-lying nature of the territory, also affected by subsidence, although not accounted for in the present assessment, the absence of natural defences (i.e. dunes) and the reduced amount of available sand to naturally nourish the beaches. Land subsidence is a critical issue when analysing coastal risk (Aucelli et al., 2016; Perini et al., 2017) and future studies should take into account this important characteristic of the regional coast.

The methodology presented was, for the flooding hazard indicator, different from the one described in (Viavattene et al., 2017), because the regional managers provided data produced for the Floods Directive (Perini et al., 2016). It was therefore possible to use flooding maps already available and derived from a different methodology than the approach proposed by Viavattene et al. (2017). Simple 1D approaches (e.g. bathtub) along profile lines could work in areas were the back barrier topography increases monotonically landwards. In low-lying areas, like the RER coastline, the bathtub approach leads to the overestimation of the flooding extension, as claimed by Gesch (2009), Murdukhayeva et al. (2013) and Perini et al. (2016). It is suggested to use bi-dimensional flood maps for CRAF Phase 1, whenever they are available. This could lead to more accurate results in terms of hotspots identification, as the presented validation points out.

The validation procedure showed that the identified critical areas were significantly consistent with the historical information on past storm events (1946-2010; Perini et al., 2011) for flooding and erosion.

The Emilia-Romagna Region can be defined as a data-rich region, where information are publicly available, where all the actors dealing with coastal issues are aware of the problems, and where there are many procedures/regulations/protocols to mitigate the impact of storms. The close cooperation with the regional managers provided important suggestions to elaborate an accurate procedure, step by step. Moreover, the application of the CRAF method in a data-rich site provided the necessary information to validate the results and demonstrated that the method for the identification of hotspots is reliable. Where the End-Users' know-how is robust, the method can be improved to obtain more consistent results. It should be underlined that the End-Users were not surprised by the 
CRAF results, as it confirmed well-known critical areas. However, the codified methodology provided by the CRAF could help improving the already existing methods, especially for the identification, valuation and ranking of the exposure indicators, and the comparison between sectors through the coastal index approach.

\section{Acknowledgements}

This work was supported by the European Community's 7th Framework Programme through the grant to RISC-KIT ("Resilience-increasing Strategies for Coasts - Toolkit"), contract 603458, and by contributions by the partner institutes. The authors are very grateful to Dott.sa Luisa Perini, Dr. Lorenzo Calabrese and Dott. Paolo Luciani of Servizio Geologico Sismico e dei Suoli (Regione Emilia-Romagna) for providing data and for their availability, exchange of ideas, comments and perceptions. The authors would also like to thank ENI for providing topo-bathymetric data. Finally, the authors thank C. Viavattene and P. Ciavola for their reviews and comments to the paper. The authors would like to thank the two anonymous reviewers for providing productive comments and suggestions.

\section{References}

Armaroli, C., Ciavola, P., Masina, M., Perini, L., 2009. Run-up computation behind emerged breakwaters for marine storm risk assessment. J. Coast. Res. 56, 1612-1616. SI.

Armaroli, C., Ciavola, P., Perini, L., Calabrese, L., Lorito, S., Valentini, A., Masina, M. 2012. Critical storm thresholds for significant morphological changes and damage along the Emilia-Romagna coastline, Italy. Geomorphology 143-144, 34-51. http:// dx.doi.org/10.1016/j.geomorph.2011.09.006.

Garnier, E., Ciavola, P., Spencer, T., Ferreira, O., Armaroli, C., McIvor, A., 2017. Historica analysis of storm events: case studies in France, England, Portugal and Italy. Coast. Eng. 134, 10-23.

Aucelli, P.P.C., Di Paola, G., Incontri, P., Rizzo, A., Vilardo, G., Benassai, G., Buonocore, B., Pappone, G., 2016. Coastal inundation risk assessment due to subsidence and sea level rise in a Mediterranean alluvial plain (Volturno coastal plain - Southern Italy). Estuar. Coast. Shelf Sci. 1-13. http://dx.doi.org/10.1016/ j.ecss.2016.06.017.

Bertoni, D., Armaroli, C., Ciavola, P., Fast retreat of a barrier system due to reduced sediment supply (Bellocchio, Northern Adriatic Sea, Italy), In: Coast. Marit. Mediterr. Conf. Ed. 3, Ferrara, Italy, 2015: pp. 7-10, http://dx.doi.org/10.5150/cmcm. 2015. 002 .

Billi, P., Rinaldi, M., 1997. Human impact on sediment yield and channel dynamics in the Arno River basin (central Italy). In: Hum. Impact Eros. Sediment. (Proceedings Rabat Symp. S6, April 1997). IAHS Press, Institute of Hydrology, Wallingford, Oxfordshire, UK, pp. 301-311.

Ciavola, P., Billi, P., Armaroli, C., Preciso, E., Salemi, E., 2005. Valutazione della morfodinamica di foce del Torrente Bevano (RA): il ruolo del trasporto solido di fondo. Geol. Tec. Ed. Ambient. 1, 41-57.

Ciavola, P., Armaroli, C., Chiggiato, J., Valentini, A., Deserti, M., Perini, L., Luciani, P., 2007. Impact of storms along the coastline of Emilia-Romagna: the morphological signature on the Ravenna coastline (Italy). J. Coast. Res. SI 50, 540-544.

Ciavola, P., Ferreira, O., Haerens, P., Van Koningsveld, M., Armaroli, C., 2011. Storm impacts along European coastlines. Part 2: lessons learned from the MICORE project. Environ. Sci. Policy 14, 924-933. http://dx.doi.org/10.1016/j.envsci.2011.05.009.

Decouttere, C., De Backer, K., Monbaliu, J., Berlamont, J., 1998. Storm wave simulation in the Adriatic sea. In: CENAS Coastline Evol. up. Adriat. Sea Due to Sea Lev. Rise Nat Anthropog. L. Subsid. Springer, Netherlands, Dordrecht, NL, pp. 185-205. http:// dx.doi.org/10.1007/978-94-011-5147-4_9.

Ferreira, Ó., Ciavola, P., Armaroli, C., Balouin, Y., Benavente, J., Del Río, L., Deserti, M., Esteves, L.S., Furmanczyk, K., Haerens, P., Matias, A., Perini, L., Taborda, R., Terefenko, P., Trifonova, E., Trouw, K., Valchev, N., Van Dongeren, A., Van Koningsveld, M., Williams, J.J., 2009. Coastal storm risk assessment in Europe: examples from 9 study sites. J. Coast. Res. 56, 1632-1636. SI.

Ferreira, O., Plomaritis, T.A., Costas, S., 2017. Process-based indicators to assess storm induced coastal hazards. Earth Sci. Rev. http://dx.doi.org/10.1016/ j.earscirev.2017.07.010. ISSN 0012-8252, in press.

Gesch, D.B., 2009. Analysis of lidar elevation data for improved identification and delineation of lands vulnerable to sea-level rise. J. Coast. Res. 53, 49-58. http:// dx.doi.org/10.2112/SI53-006.1.

Harley, M.D., Ciavola, P., 2013. Managing local coastal inundation risk using real-time forecasts and artificial dune placements. Coast. Eng. 77, 77-90. http://dx.doi.org/ 10.1016/j.coastaleng.2013.02.006.

Harley, M.D., Valentini, A., Armaroli, C., Perini, L., Calabrese, L., Ciavola, P., 2016. Can an early-warning system help minimize the impacts of coastal storms? A case study of the 2012 Halloween storm, Northern Italy. Nat. Hazards Earth Syst. Sci. 16, 209-222. http://dx.doi.org/10.5194/nhess-16-209-2016.
Ciavola, P., Harley, M.D., den Heijer, C., 2017. The RISC-KIT storm impact database: a new tool in support of DRR. Coast. Eng. 134, 24-32.

IDROSER, 1981. Piano progettuale per la difesa della costa adriatica EmilianoRomagnola. Bologna, Italy.

IDROSER, 1996. Progetto di Piano per la difesa del mare e la riqualificazione ambientale del litorale della Regione Emilia-Romagna. Bologna, Italy.

ISPRA, 2012. Annuario dei dati Ambientali 2011, Istituto Superiore per la Protezione e la Ricerca Ambientale. Rome, Italy. http://www.isprambiente.gov.it/files/ pubblicazioni/statoambiente/tematiche2011.

Jiménez, J.A., Armaroli, C., Berenguer, M., Bosom, E., Ciavola, P., Ferreira, O. Plomaritis, H., Roelvink, D., Sanuy, M., Sempere, D., 2015. Deliverable No: D.2.1Coastal Hazard Assessment Module.

Lorito, S., Calabrese, L., Perini, L., Cibin, U., 2010. Uso del suolo della costa. In: Perini, L., Calabrese, L. (Eds.), Sist. Mare-Costa dell'Emilia-Romagna, Regione Emilia-Romagna, pp. 109-118. Bologna, Italy.

Masina, M., Ciavola, P., 2011. Analisi dei livelli marini estremi e delle acque alte lungo il litorale ravennate. Stud. Costieri 18, 87-101.

Mendoza, E.T., Jimenez, J.A., 2006. Storm-induced beach erosion potential on the catalonian coast. J. Coast. Res. 48, 81-88.

Murdukhayeva, A., August, P., Bradley, M., LaBash, C., Shaw, N., 2013. Assessment of inundation risk from sea level rise and storm surge in northeastern coastal national parks. J. Coast. Res. 29, 1-16. http://dx.doi.org/10.2112/JCOASTRES-D-1200196.1.

Nordstrom, K.F., Armaroli, C., Jackson, N.L., Ciavola, P., 2015. Opportunities and constraints for managed retreat on exposed sandy shores: examples from EmiliaRomagna, Italy. Ocean. Coast. Manag. 104, 11-21. http://dx.doi.org/10.1016/ j.ocecoaman.2014.11.010.

Perini, L., Carrara, G., Luciani, P., Lorito, S., Calabrese, L., 2010a. Batimetrie e modelli digitali dei fondali. In: Perini, L., Calabrese, L. (Eds.), Sist. Mare-costa Dell'EmiliaRomagna, pp. 67-86. Regione Emilia-Romagna, Bologna, Italy.

Perini, L., Luciani, P., Calabrese, L., 2010b. Altimetria della fascia costiera. In: Perini, L., Calabrese, L. (Eds.), Sist. Mare-costa Dell'Emilia-Romagna, pp. 57-66. Regione Emilia-Romagna, Bologna, Italy.

Perini, L., Calabrese, L., Deserti, M., Valentini, A., Ciavola, P., Armaroli, C., 2011. Le mareggiate e gli impatti sulla costa in Emilia-Romagna 1946-2010. ARPA EmiliaRomagna, Bologna, Italy.

Perini, L., Calabrese, L., Lorito, S., Luciani, P., Costal flood risk in Emilia-Romagna (Italy): the sea storm of February 2015, In: Coast. Marit. Mediterr. Conf. Ed. 3, Ferrara, Italy, 2015: pp. 225-230. http://dx.doi.org/10.5150/cmcm.2015.044.

Perini, L., Calabrese, L., Salerno, G., Ciavola, P., Armaroli, C., 2016. Evaluation of coastal vulnerability to flooding: comparison of two different methodologies adopted by the Emilia-Romagna region (Italy). Nat. Hazards Earth Syst. Sci. 16, 181-194. http:// dx.doi.org/10.5194/nhess-16-181-2016.

Perini, L., Calabrese, L., Luciani, P., Olivieri, M., Galassi, G., Spada, G., 2017. Sea-level rise along the Emilia-Romagna coast (Northern Italy) at 2100: scenarios and impacts. Nat. Hazards Earth Syst. Sci. Discuss. http://dx.doi.org/10.5194/nhess-2017-82 in review.

Preciso, E., Salemi, E., Billi, P., 2012. Land use changes, torrent control works and sediment mining: effects on channel morphology and sediment flux, case study of the Reno River (Northern Italy). Hydrol. Process 26, 1134-1148. http://dx.doi.org/ 10.1002/hyp.8202.

Sekovski, I., Armaroli, C., Calabrese, L., Mancini, F., Stecchi, F., Perini, L., 2015. Coupling scenarios of urban growth and flood hazards along the Emilia-Romagna coast (Italy). Nat. Hazards Earth Syst. Sci. 15, 2331-2346. http://dx.doi.org/10.5194/nhess-152331-2015.

Sytnik, O., Stecchi, F., 2014. Disappearing coastal dunes: tourism development and future challenges, a case-study from Ravenna, Italy. J. Coast. Conserv. 19, 715-727. http:// dx.doi.org/10.1007/s11852-014-0353-9.

Tapsell, S.M., Penning-Rowsell, E.C., Tunstall, S.M., Wilson, T.L., 2002. Vulnerability to flooding: health and social dimensions. Philos. Trans. R. Soc. Lond. A Math. Phys. Eng. Sci. 360, 1511-1525. http://dx.doi.org/10.1098/rsta.2002.1013.

Taramelli, A., Di Matteo, L., Ciavola, P., Tolomei, C., 2015. Temporal evolution of patterns and processes related to subsidence of the coastal area surrounding the Bevan River mouth (Northern Adriatic) - Italy. Ocean Coast. Manag. 108, 74-88.

Teatini, P., Ferronato, M., Gambolati, G., Bertoni, W., Gonella, M., 2005. A century of land subsidence in Ravenna, Italy. Environ. Geol. 47, 831-846. http://dx.doi.org/ 10.1007/s00254-004-1215-9.

Trembanis, A.C., Duo, E., Dohner, S., Grottoli, E., Ciavola, P., 2017. Quick response assessment of the impact of an extreme storm combining aerial drone, RTK GPS, and morphodynamic modeling. Coast. Eng. under review.

Van der Meer, J.W., Daemen, I.F.R., 1994. Stability and wave transmission at low-crested rubble-mound structures. J. Waterw. Port. Coast. Ocean. Eng. 120, 1-19.

Van Dongeren, A., Ciavola, P., Martinez, G., Viavattene, C., Bogaard, T., Ferreira, Ó. Higgins, R., McCall, R., 2017. Introduction to RISC-KIT: resilience-increasing strategies for coasts. Coast. Eng. 134, 2-9.

Viavattene, C., Micou, A.P., Owen, D., Priest, S., Parker, D., 2015. Library of Coastal Vulnerability Indicators, Guidance Document. Deliverable No: D.2.2 -Coastal Vulnerability Indicator Library. http://www.risckit.eu/np4/file/23/RISC_KIT_D.2.2 CVIL_Guidance Document.pdf.

Viavattene, C., Jiménez, J.A., Ferreira, O., Priest, S., Owen, D., McCall, R., 2017. Selecting coastal hotspots at the regional scale: the coastal risk assessment framework. Coast. Eng. 